\title{
Beyond Abigail Alliance: The Reality Behind the Right to Get Experimental Drugs
}

\author{
Jerry Menikoff
}

One of the more exciting recent events in constitutional law has been the possibility of a newly coined constitutional right: a right of access to unproven medications. For at least one brief moment in time, as a result of the litigation stemming from a young woman's quest to get access to a possibly life-saving drug, that right seemed closer to reality than ever before. Given the highly regulated nature of the American health care system, such a right promised to make profound changes in the lives of many people.

That intriguing possibility was quickly snuffed out, as the litigation generated by the Abigail Alliance for Better Access to Developmental Drugs (the Alliance) moved on to a less compelling outcome. ${ }^{1}$ But the issues that arose during the intervening months of excitement are important ones and continue to be worth evaluating. This Article will attempt to demonstrate that much of the claimed promise regarding a constitutional right of access to unproven medicines is largely hype. For a variety of reasons, such a right is likely to have a relatively modest impact on the lives of most Americans.

This Article will discuss in Part I the history, prior to recent events, of this constitutional right; in Part II, the Abigail Alliance for Better Access to Developmental Drugs v. von Eschenbach ${ }^{2}$ case; in Part III, the reasons why the creation of such a constitutional right would be of far less consequence than many believe; and in Part IV, how the issue of access to unproven medications is already playing out in an area that receives relatively little acknowledgement-participation in clinical trials.

Director, Office of Human Subjects Research, and Bioethicist, Department of Bioethics, National Institutes of Health; Associate Professor of Law, Ethics \& Medicine, University of Kansas (on leave). The opinions expressed are mine and do not necessarily reflect the policy of the National Institutes of Health or the U.S. Department of Health and Human Services.

1. See infra Part II.

2. 495 F.3d 695 (D.C. Cir. 2007), cert. denied, 128 S. Ct. 1069 (2008). 


\section{THE EARLY HISTORY}

Back in the late 1970s, when there were far fewer celebrities than there are today, it was big news when movie star Steve McQueen became seriously ill. McQueen had been the picture of vigor both on and off the screen. In numerous movie roles, from the car chase scenes in Bullitt to his portrait of the cheerfully defiant prisoner of war in The Great Escape, he always seemed to manage to come out a winner. ${ }^{3}$ And even in the glimpses of his private life, he would similarly be seen engaged in adventurous pursuits, most often in the driver's seat of a race car.

But things began to go downhill in 1978 when he first developed a cough, which led to his having difficulty breathing by $1979 .{ }^{4}$ In December of that year, at the relatively youthful age of forty-nine, the diagnosis of mesothelioma, a relatively rare form of lung cancer that is most commonly caused by exposure to asbestos, was made. ${ }^{5} \mathrm{He}$ eventually went to Mexico to receive injections of Laetrile, a treatment made of ground-up apricot pits. ${ }^{6}$

The circumstances leading up to McQueen's death in 1980 were merely one prominent instance of a much broader debate that was taking place in this country at the time. The actor had not gone to Mexico for reasons of convenience, or even because he felt the Mexican clinic would provide superb care. The simple fact was that he could not obtain Laetrile in the United States. The Food and Drug Administration (FDA), exercising its authority under the Food, Drug, and Cosmetic Act (FDCA), ${ }^{7}$ had banned the distribution of Laetrile in interstate commerce. ${ }^{8}$ It had determined that the compound had not been shown to meet the statutory standards required before such interstate sale. There was

3. See Barron H. Lerner, McQueen's Legacy of Laetrile, N.Y. TimEs, Nov. 15, 2005, at F5.

4. Id.

5. Id. Some suggest that he might have been exposed to asbestos from the racing suits he wore when he was racing cars. Id.

6. Id. The Food and Drug Administration has the viewpoint that there is no "uniform" definition of Laetrile, though it is used "generically" to refer to compounds that contain amygdalin, which is a glucoside that is found in the "kernels or seeds" of most fruits. United States v. Rutherford, 442 U.S. 544, 549 (1979). The active ingredient in Laetrile is believed to be cyanide. Clinical trials were eventually conducted to test the safety and efficacy of Laetrile in cancer patients. They demonstrated substantial side effects due to cyanide poisoning and, more importantly, no benefit to the research subjects. Charles G. Moertel, et al., A Clinical Trial of Amygdalin (Laetrile) in the Treatment of Human Cancer, 306 NEw ENG. J. MED. 201, 204-06 (1982).

7. 21 U.S.C. $\S \S 301-97(2000)$.

8. Rutherford, 442 U.S. at 548. 
neither proof of its safety nor of its efficacy in treating a particular medical condition. ${ }^{9}$

This state of affairs did not sit well with certain groups of Americans. They felt that this constituted inappropriate government interference with what were essentially very private and difficult decisions. At the very time that McQueen was dying, a group of patients dying from untreatable terminal cancers had brought suit against the FDA in federal court. They argued that the provisions of the FDCA should not apply to their special circumstances and therefore the FDA had no authority to interfere with their attempts to obtain Laetrile. ${ }^{10}$

The district court hearing the lawsuit found in favor of the plaintiffs, determining that Laetrile, in certain doses, was both safe and effective. On appeal, the Court of Appeals for the Tenth Circuit returned the case to the district court and required the FDA to make a determination of whether Laetrile was a "new drug" as defined in the FDCA and, if so, whether it might come under certain grandfathering provisions of that Act. ${ }^{11}$ The FDA then determined Laetrile was indeed a new drug as defined in the Act, but that the grandfathering provisions did not apply. The district court, upon reviewing these FDA determinations, concluded that the FDA was wrong in its analysis of the most recent grandfathering rules, and that, alternatively, even if Laetrile was not grandfathered, then the FDA's actions violated the U.S. Constitution in that they conflicted with the privacy interests of these patients, which protected their use of a non-toxic substance for treating a health problem. ${ }^{12}$

The second time that the lawsuit reached the court of appeals, the court chose to address neither the constitutional issue nor the statutory analysis performed by the district court. Instead, the Tenth Circuit panel concluded that the provisions of the FDCA relating to the need for proving a drug both safe and effective had no meaningful relevance to the circumstances of terminally ill cancer patients like the plaintiffs. ${ }^{13}$ Specifically, it determined that in the case of such patients, who are going to die regardless of any other treatments they are given, "there were no realistic standards against which to measure the safety and effectiveness of a drug." ${ }^{14}$ Accordingly, subject to some modest

9. See id. at 550 .

10. See id. at 548, 551 (describing the relief sought and discussing whether the FDCA makes special provision for drugs to treat the terminally ill).

11. Id. at 549 .

12. Id. at $549-50$.

13. Id. at $550-51$.

14. Id. at 551 (summarizing the conclusion of the court of appeals). 
requirements (such as having a doctor supervise the administration of the Laetrile), the court concluded that the FDA had no authority to prevent the plaintiffs from using Laetrile. ${ }^{15}$

It was against this background that the case reached the U.S. Supreme Court in 1979. The Supreme Court performed its own analysis of both the relevant statutory history and language of the FDCA. It noted that the wording of the Act contained no special rules relating to drugs that will be used for treating cancer or any other disease in terminally ill patients. Nor, in its view, was there anything in the history of the Act that justified reading in such an exception. ${ }^{16}$

In its review of that statutory history, the Supreme Court observed that members of Congress had specifically mentioned patients suffering from incurable diseases, including cancer, as being members of the group that needed protection from "fraudulent cures." 17 The FDA had never interpreted the statute as embodying any exceptions for that group, and throughout the long period in which that unvarying interpretation was applied, Congress had given no indication that the FDA interpretation was incorrect. Given that set of circumstances, the Supreme Court felt it would be especially inappropriate to overturn the longstanding FDA position, which was entitled to substantial deference. ${ }^{18}$

The Supreme Court separately took issue with the conclusion of the court of appeals that the concepts of "safety" and "efficacy" have "no reasonable application' to terminally ill patients." ${ }^{\prime 19}$ Regarding efficacy, for example, there might well be evidence that a drug could produce useful results for a cancer patient even if it cannot cure the patient. It could reduce pain or extend the patient's life, among other things. And as for safety, the evaluation of safety for any drug involves comparing its benefits to the possible harms it might cause. That type of tradeoff could certainly be evaluated for drugs to be used in treating terminal cancer patients.

The Supreme Court was particularly concerned about one element of this equation: the harm a drug might cause if people turned to it when there were proven treatments that had better benefit-risk relationships. ${ }^{20}$

15. Id.

16. Id. at $552-53$.

17. Id. at 552 .

18. Id. at $553-54$.

19. Id. at 554-56 (quoting Rutherford v. United States, 582 F.2d 1234, 1236 (10th Cir. 1978), rev'd, 442 U.S. 544 (1979)).

20. Id. at 556. 
It noted the untoward results that might take place if the plaintiffs' analysis of the law was accepted:

It bears emphasis that although the Court of Appeals' ruling was limited to Laetrile, its reasoning cannot be so readily confined. To accept the proposition that the safety and efficacy standards of the Act have no relevance for terminal patients is to deny the Commissioner's authority over all drugs, however toxic or ineffectual, for such individuals. If history is any guide, this new market would not be long overlooked. Since the turn of the century, resourceful entrepreneurs have advertised a wide variety of purportedly simple and painless cures for cancer, including liniments of turpentine, mustard, oil, eggs, and ammonia; peat moss; arrangements of colored floodlamps; pastes made from glycerin and limburger cheese; mineral tablets; and 'Fountain of Youth' mixtures of spices, oil, and suet. In citing these examples, we do not, of course, intend to deprecate the sincerity of Laetrile's current proponents, or to imply any opinion on whether that drug may ultimately prove safe and effective for cancer treatment. But this historical experience does suggest why Congress could reasonably have determined to protect the terminally ill, no less than other patients, from the vast range of self-styled panaceas that inventive minds can devise. ${ }^{21}$

And in making this pronouncement, the Supreme Court also had reason to believe that it was not totally foreclosing access to unproven medications such as Laetrile. If such a drug ended up being approved by the FDA for testing in clinical research studies, then patients could enroll in such studies. ${ }^{22}$

In reversing the lower court's holding, the Supreme Court was merely upholding the FDA's authority as given to it by Congress. It never addressed the constitutional issues that had been discussed in the original district court opinion. While one can treat the Supreme Court's failure to address the constitutional question as merely appropriate judicial discretion, given the procedural posture of the case, few people would have expected the Supreme Court to reach a different outcome had it been forced to confront that question. At the time, there was a great deal of enthusiasm for allowing greater access to non-FDAapproved drugs. Numerous amici curiae had filed briefs before the Supreme Court supporting the position of the plaintiffs. And the desperate circumstances of the terminal patients seeking Laetrile and similar drugs were not altered by the Supreme Court's decision. Thus, had there been even a small hope that the Supreme Court would rule in

21. Id. at 557-58 (footnote omitted).

22. Id. at 558 
favor of greater access if the right case came before it, substantial efforts would likely have been made to get such a case to the Supreme Court. But that scenario did not take place.

Indeed, until recently, there have been virtually no judicial opinions supporting the existence of a constitutional right that overrides the FDA's authority to control access to drugs that have not been proven both safe and effective. ${ }^{23}$ Thus, a great deal of interest was generated when the events relating to Abigail Burroughs and the Alliance started to build momentum in 2006 .

\section{THE ABIGAIL ALLIANCE LITIGATION}

Abigail Kathleen Burroughs was a student at the University of Virginia when she was discovered to have squamous cell carcinoma, a type of head and neck cancer that usually occurred only in much older people. ${ }^{24}$ She first tried to get treated with the experimental drug Iressa, but she did not qualify for the clinical trials in which it was being studied. $^{25}$ Her doctor at Johns Hopkins Hospital told her of another experimental drug called Erbitux that had shown some promise in research studies for treating other types of cancer. She tried to enroll in a clinical trial for that drug, but again she did not meet the eligibility criteria because it was only being studied in colon cancer patients. ${ }^{26}$ She was also not able to get the drug from the manufacturer under a compassionate-use program, which is the usual mechanism for getting unapproved medicines to people who do not qualify for clinical trials. ${ }^{27}$

Abigail died in June 2001 at the age of twenty-one, and in her memory her father, Frank Burroughs, created the Alliance as an advocacy organization that would fight for the right of patients to greater access to unproven drugs. ${ }^{28}$ An early step taken by that entity was to file a citizen petition with the FDA urging it among other things to "expand availability of investigational drugs to the terminally ill by allowing compassionate use programs to begin at an earlier stage of the approval

23. See Abigail Alliance for Better Access to Developmental Drugs v. von Eschenbach, 495 F.3d 695, 710 n.18 (D.C. Cir. 2007) (reviewing cases).

24. Complaint at 2, Abigail Alliance, 495 F.3d 695 (No. 04-5350), available at http://www.abigail-alliance.org/WLF_FDA_Lawsuit.pdf; Sue Kovach, The Abigail Alliance: Motivated by Tragic Circumstances, Families Battle an Uncaring Bureaucracy, LIFE EXTENSION, Sept. 2007, at 67, 68 .

25. Complaint, supra note 24 , at 7.

26. Id. at 10 .

27. See id. at 6-7.

28. Kovach, supra note 24. 
process." 29 That petition did not raise any constitutional claims, and the FDA did not respond to it. ${ }^{30}$

Following up on the lack of results from the petition, one of the next steps taken by the Alliance was to join forces with the conservative Washington Legal Foundation in a lawsuit against the FDA to enjoin that agency "from continuing to enforce a policy that violates the constitutional privacy and liberty rights of terminally ill patients ... and their constitutional guarantee against deprivation of life without due process." ${ }^{31}$ The plaintiffs alleged violations of the Fifth and Fourteenth Amendments. ${ }^{32}$

In the complaint, the Alliance described the current system for getting FDA approval of a new drug. ${ }^{33}$ In general, the drug has to go through years of testing. First, in a Phase I study, a few people are given the drug to determine how large a dose can be given until unacceptable side effects appear. Then, in a larger Phase II study, researchers perform initial testing for efficacy. If both of those hurdles are met, the drug may finally enter a Phase III study where hundreds of people are usually randomized to get either the new drug or some other proven treatment or a placebo. During that long process, as the Alliance acknowledged, there are a few ways for patients to get the drug. One is to become a participant in those research studies. The Alliance claimed that the number of spots in such trials was relatively small in comparison to the number of people who might "need" the new drug.

The second method for getting the unproven drug was to obtain it through a compassionate-use program, which the complaint described as follows:

Existing "compassionate use" programs for new drugs, under which drug companies may opt voluntarily to provide drugs to a limited number of patients during this pre-approval period, accommodate only a small number of patients - again, a fraction of those in desperate need. "Compassionate use" programs are small, when they exist at all, because drug sponsors may not charge more than a cost recovery amount to participants. Promising new drugs thus remain generally unavailable to patients even though there is evidence of the drugs'

\footnotetext{
29. Complaint, supra note 24 , at 9.

30. Id. at 10 .

31. Id. at 1 .

32. Id. at 11 .

33. Id. at $4-6$.
} 
safety and efficacy, and even though the patients have no alternative to the drugs other than to wait for their own death. ${ }^{34}$

The district court, not surprisingly, dismissed the lawsuit, concluding that the plaintiffs failed to state a claim. ${ }^{35}$ With regard to the proposition that there is a constitutional right of access to experimental drugs, the court noted that the precedents cited by the plaintiffs failed to make that case. In particular, the Supreme Court, in cases such as Cruzan v. Director, Missouri Department of Health ${ }^{36}$ and Washington $v$. Glucksberg, ${ }^{37}$ had merely recognized that there is a constitutional right to prevent things from being done to our bodies against our wishes. That proposition in no way was the same as the "flip side" of the coin, involving the right to obtain certain types of medical care. ${ }^{38}$ Having concluded that no constitutional right was at issue, the court went on to determine that there was clearly a rational relationship between the FDA policy and a legitimate state interest, and thus the policy was constitutional. $^{39}$

On appeal to the Court of Appeals for the D.C. Circuit, the district court decision was reversed. ${ }^{40}$ In a surprising opinion, the two-judge majority concluded that there was indeed a constitutional right at stake. ${ }^{41}$ In reaching this result, the court applied the more recent, and more restrictive, of the Supreme Court's two approaches for determining whether a right merits constitutional protection. ${ }^{42}$ Under that approach, the right must be "objectively, 'deeply rooted in this Nation's history and tradition," and it must be "implicit in the concept of ordered liberty, such that neither liberty nor justice would exist if [it] were sacrificed."'43

In applying that test, the court of appeals noted the importance of first carefully describing what the proposed right is. It found that the

\footnotetext{
34. Id. at 6 .

35. Abigail Alliance for Better Access to Developmental Drugs v. McClellan, No. 03-1601, 2004 WL 3777340 , at $* 12$ (D.D.C. Aug. 30, 2004), aff'd sub nom. Abigail Alliance for Better Access to Developmental Drugs v. von Eschenbach, 495 F.3d 695 (D.C. Cir. 2007).

36. 497 U.S. 261 (1990) (involving the right to refuse unwanted medical treatments).

37. 521 U.S. 702 (1997) (concluding that there is no right to physician-assisted suicide).

38. Abigail Alliance, $2004 \mathrm{WL} 3777340$, at *10-11.

39. Id. at $11-12$.

40. Abigail Alliance for Better Access to Developmental Drugs v. von Eschenbach, 445 F.3d 470 (D.C. Cir. 2006), vacated, No. 04-5350, 2006 U.S. App. LEXIS 28974 (D.C. Cir. 2006).

41. Id. at 477.

42. Id. at $476-77$.

43. Id. (quoting Washington v. Glucksberg, 521 U.S. 702, 720-21 (1997) (alteration in original)).
} 
Alliance had done a good job of narrowly describing the right. ${ }^{44}$ The Alliance was claiming "neither an unfettered right of access to all new or investigational drugs nor a right to receive treatment from the government or at government expense." ${ }^{45}$ Rather, it sought recognition of "the right of terminally ill patients, acting on a doctor's advice, to obtain potentially life-saving medication when no alternative treatment approved by the government is available. ... [T] he Alliance ask[ed] only that the decision to assume these known or unknown risks be left to the terminally ill patient and not to the FDA." $" 46$

Applying the Supreme Court's test to this proposed fundamental right, the court noted that the right to control one's body "has deep roots in the common law," including the right to self-defense and selfpreservation. ${ }^{47}$ The majority went on to determine that "[b]arring a terminally ill patient from the use of a potentially life-saving treatment impinges on this right of self-preservation." 48 In contrast to that ancient right was the recent origin of governmental efforts to prevent access to such treatments. The first true restrictions on a person's right to obtain the drugs of his or her choice did not come into being until 1938, with enactment of the FDCA. ${ }^{49}$ And even those limitations were substantially weaker than the ones that were enacted in later revisions of the FDCA. As the court summed it up, "[f]or over half of our Nation's history ... a person could obtain access to any new drug without any government interference whatsoever." 50

As to the claimed right being "implicit in the concept of ordered liberty," the court quoted Justice Rehnquist's observation in Cruzan that the right to refuse unwanted medical treatment was likely constitutionally protected. It concluded that it was a logical corollary that, if a person has the right to make decisions about withdrawing treatment, then that person similarly must have the right to make decisions about whether or not to take a medication that might prolong his or her life. ${ }^{51}$

44. Id. at 478 .

45. Id.

46. Id.

47. Id. at 480 .

48. Id.

49. See id. at 482 (discussing Congress's first attempt to regulate the testing of new drugs).

50. Id. at 483 .

51. Id. at 484. In his dissent, Judge Griffith took issue with many of the conclusions of the majority, and particularly its determination that a constitutional right existed. As he put it, the "decision to procure and use experimental drugs has never enjoyed legal protection, let alone risen to the level of a 'fundamental right." Id. at 497 (Griffith, J., dissenting) (quoting Washington v. Glucksberg, 521 U.S. 702, 720-21 (1997)). 
The court's opinion, not surprisingly, attracted a great deal of attention. The defendants filed a motion for en banc consideration by the court of appeals. In November 2006, the court vacated the panel's decision and granted the request for en banc review. ${ }^{52}$ In August 2007, that en banc review, by a vote of eight to two, affirmed the district court's judgment that there was no such constitutional right. ${ }^{53}$

In its analysis, the court of appeals first addressed the argument that "“common law and historical American practices have traditionally trusted individual doctors and their patients with almost complete autonomy to evaluate the efficacy of medical treatments." 54 The Alliance maintained, as a major element of its position, that only since 1962 has the federal government regulated the efficacy of drugs. But the court observed that this left out a much longer-standing form of government regulation, namely, that directed at the safety of drugs. For the Alliance to succeed, noted the court, it must prove that there was a tradition of access to drugs that were not yet proven safe. ${ }^{55}$ In analyzing that proposition, the court found that as early as 1736 , this nation had begun the regulation of unsafe drugs. ${ }^{56}$ And during the 270 years that followed, there were numerous other such regulatory efforts made at both the state and federal levels. ${ }^{57}$

The court next turned to the Alliance's claim that several commonlaw doctrines supported the finding of a constitutional right. That approach was similar to what the Supreme Court had done in Cruzan, where it used the tort of battery to conclude that there might well be a liberty interest in avoiding unwanted medical care. ${ }^{58}$ The doctrines on which the Alliance relied were the doctrine of necessity, the tort of intentional interference with lifesaving efforts, and the right to selfdefense. $^{59}$ The Alliance claimed that all three of these supported a right

52. Abigail Alliance for Better Access to Developmental Drugs v. von Eschenbach, No. 045350, 2006 U.S. App. LEXIS 28974 (D.C. Cir. 2006).

53. Abigail Alliance for Better Access to Developmental Drugs v. von Eschenbach, 495 F.3d 695, 697 (D.C. Cir. 2007), cert. denied, 128 S. Ct. 1069 (2008).

54. Id. at 702-03 (quoting appellants' brief).

55. Id. at 703 .

56. Id. at $703-04$.

57. Id. at 703-05. The court also noted that even if there were not a tradition of a particular type of regulation, such as regulation of drug efficacy, such lack of regulation could not obviously by itself be sufficient to demonstrate the existence of a fundamental right. Such an argument proves too much, since presumably we would then have to conclude that there was a liberty interest in using marijuana, and that speed limits are unconstitutional. Id. at 706-07 (noting that marijuana regulation and speed limits did not exist until relatively recently).

58. See id. at $711 \mathrm{n} .19$ (summarizing and distinguishing Cruzan).

59. Id. at 707. 
to self-preservation, a right that would allegedly embody the ability to use experimental drugs.

The court made short shrift of the necessity argument, noting that the Supreme Court had already labeled this as a controversial doctrine, and thus it was meager support for a new constitutional right. ${ }^{60}$ Regarding the tort of interference with lifesaving efforts, that tort was defined to involve preventing someone from providing aid that is "necessary." Given that the drugs involved in the case had not yet been proven either safe or effective, it appeared to be a stretch to claim that they somehow could be characterized as "necessary" aid. ${ }^{61}$

Regarding the common-law right to self-defense, the court concluded that "this case is not about using reasonable force to defend oneself (as in most cases involving self-defense), nor is it about access to life-saving medical treatment." $"$ It noted that the use of the experimental treatments had been characterized by the plaintiffs as involving "enormous risks." Thus, it was inappropriate to draw an analogy between using "reasonable force" and the use by terminally ill patients of drugs that have been proven neither safe nor effective.

Having rejected the arguments in favor of recognizing a constitutional right, the court proceeded to conduct a rational relationship analysis of the FDA rules. Like the district court, the court of appeals had no difficulty finding that those rules were rationally related to a legitimate state interest. ${ }^{63}$ In making its determination, the court favorably quoted language from the Rutherford case: "For the terminally ill, as for anyone else, a drug is unsafe if its potential for inflicting death or physical injury is not offset by the possibility of therapeutic benefit." enforce rules that prevented even dying patients from getting access to drugs of unproven benefit.

This rather prosaic resolution of the issues in Abigail Alliance should not be allowed to overshadow a remaining fascinating aspect of these events. Surely, the struggle by terminally ill patients to get the next possibly lifesaving breakthrough treatment is one with which most of us can empathize. But in trying to reach that goal by litigating about a constitutional right to unproven medications, perhaps the plaintiffs were

\footnotetext{
60. Id. at 708 .

61. Id. at 709 .

62. Id. at $709-10$.

63. Id. at $712-13$.

64. Id. at 713 (quoting United States v. Rutherford, 442 U.S. 544, 555-56 (1979)).
} 
seriously misunderstanding broader aspects of the world of cutting-edge treatments.

\section{Why a CONSTitutional Right Does Not MATter All That $\mathrm{MUCH}$}

With the Rutherford and Abigail Alliance cases as background, it is time to ask (and answer) a question: does all of the concern about the existence of a constitutional right to drugs that have not yet been fully approved by the FDA really matter? The answer would appear to be "not much." While it may be overkill to characterize the debate regarding this constitutional right as much ado about nothing, it is at least the case that, in terms of the ultimate effect on the well-being of patients, there is far less at stake than many would suggest.

The starting point in this analysis lies with the fundamental nature of such a constitutional right. As with most constitutional rights, it would merely be a limitation on the powers of the government. The right would therefore prevent the government from taking certain types of actions. It would not, however, give any individual the power to order the government - or, more importantly, any private individual - to take any affirmative actions.

Applying this concept to the specifics of the Abigail Alliance case, the only remedy the plaintiffs would have gotten, had they won, is an order preventing the FDA from interfering (within the limits established by the constitutional right) with their efforts to obtain the drugs they were seeking. The FDA would not have been ordered to take any active measures to make sure the plaintiffs could indeed obtain these drugs. Nor would a victory have provided the plaintiffs with any right to order drug companies, or any other private individuals or organizations, to provide the drugs. The only thing at issue was the elimination of the allegedly unconstitutional FDA interference with their attempts to get these drugs.

Given that explanation of what was at stake, an obvious question arises: what specifically was the FDA doing that interfered with the ability of the plaintiffs to get the drugs? An examination of the facts suggests that the FDA "interference" was much more subtle than one might guess from hearing the claims of the plaintiffs and their supporters.

Before beginning that examination, an elaboration on the rules relating to access to non-FDA-approved medications is necessary. ${ }^{65}$

65. See supra text accompanying notes 33-34. 
Since these drugs have not yet been approved by the FDA for any use, the most common way to legally obtain them is to participate in the type of research study known as a clinical trial. Those trials have complex eligibility criteria, and there are many reasons why a person with a particular disease would not qualify for a particular protocol. ${ }^{66}$

One such reason that bears special mention is the fact that a clinical trial would usually be studying a new drug as a treatment for only one disease, such as a particular form of cancer. But new cancer drugs are often eventually found to be useful in treating a variety of different cancers. Thus, a person with a type of cancer that is different from the one being studied in the clinical trial might have reason to want access to the drug. This is exactly what happened to Abigail Burroughs in her attempt to be treated with Erbitux. The drug was at that time being studied as a treatment for colorectal cancer, but she had head and neck cancer. ${ }^{67}$

People in Abigail's circumstances, who want access to an unapproved drug but are unable to participate in a clinical trial, are not always completely out of luck. The FDA has created procedures, some of them long-standing, for allowing these people to get access to unapproved drugs. ${ }^{68}$ One such procedure is informally referred to as a compassionate-use investigational new drug application (IND) ${ }^{69}$ This procedure is designed to allow access by a large number of patients to an unapproved drug. It has a variety of requirements that must be met before such an application could be approved, including that the drug has to be intended for treating a serious or life-threatening disease, that there are no comparable or otherwise adequate treatments already available, and that a clinical trial evaluating the drug is already taking place. ${ }^{70}$ Also there are other FDA procedures, such as one for getting access under

66. One important side issue should be mentioned here. Being enrolled in a clinical trial does not automatically give a patient access to a drug. Many such trials are randomized studies, and thus, depending on the arm of the study to which a person is randomized, that person may end up being assigned to standard care and not to the experimental drug that he or she really wants. Given that circumstance, if there are other good ways to obtain access to the drug, but those ways require that a person first be found ineligible for an on-going clinical trial, the person might have an incentive to intentionally make him or herself ineligible or to lie about certain aspects of his or her medical condition in order to be categorized as ineligible. This might then lead to difficulty in recruiting patients for these trials. See infra notes 98-99 and accompanying text.

67. Complaint, supra note 24, at 6-7.

68. See Expanded Access to Investigational Drugs for Treatment Use, 71 Fed. Reg. 75,147, 75,148-49 (proposed Dec. 14, 2006) (to be codified at 21 C.F.R. pt. 312) [hereinafter Expanded Access] (reviewing procedures).

69. See 21 C.F.R. § 312.34(a) (2008).

70. Id. §312.34(b)(i)-(iii). 
emergency-use conditions, ${ }^{71}$ that are viewed by the FDA as more appropriate for use in obtaining access for individual patients. ${ }^{72}$

The FDA, while in the midst of the Abigail Alliance litigation, issued a proposal to amend these expanded-access rules. ${ }^{73}$ It no doubt was feeling pressured not only by the litigation, but also by efforts in Congress to change the law so that patients would have greater access to unapproved drugs. In fact, several years earlier, as part of the Food and Drug Administration Modernization Act of 1997 (FDAMA), Congress had highlighted the agency's authority to grant such access. ${ }^{74}$ Presumably, by proposing these new rules, the FDA would lessen the likelihood that Congress would impose its own solution by taking action that went beyond what it did in 1997.

In any event, the proposed new rules, by the FDA's own description, suggest that the agency was not really changing things a great deal. ${ }^{75}$ The FDA noted that it had been the target of a variety of criticism regarding its administration of the existing rules, "includ[ing] inconsistent application of access policies and programs and inequities in access based on the relative sophistication of the setting in which a patient is treated or on the patient's disease or condition." ${ }^{, 76}$ The proposed new rules describe "in detail" the criteria for expanded access. The FDA indicated that its primary goal in promulgating these changes was "to increase awareness and knowledge of expanded access programs and the procedures for obtaining investigational drugs." $" 77$ Thus, it was not so much that the underlying rules were being changed, but rather that people would become more aware of the already-existing options for getting access to unapproved drugs.

Were the existing FDA rules a major-or even significant-factor in preventing the plaintiffs in the Abigail Alliance lawsuit from getting

71. See id. $\S 312.36$.

72. Expanded Access, supra note 68, at 75,148-49.

73. Id. at 75,147 .

74. Id. at 75,149 .

75. Expanded Access May Force Clinical Trial Changes, Guide to Good CliniCal PraC., May 2007, at 2, 2 (quoting Scott Gottlieb, a former FDA deputy commissioner, as saying that the new regulations "basically just codified what the agency already was doing").

76. Expanded Access, supra note 68, at 75,149.

77. Id. The rules go on to note that

[i]ncreased knowledge and awareness about expanded access options should make investigational drugs more widely available in appropriate situations. Clearly articulated procedures for obtaining investigational drugs for treatment use should ease the administrative burdens on individual physicians seeking investigational drugs for their patients, as well as the burdens on sponsors who make investigational drugs available for treatment use.

Id. 
access to the drugs they sought? An examination of the complaint helps to answer that question. The complaint gave details regarding the circumstances of four patients, one of whom was Abigail Burroughs. ${ }^{78}$ As noted above, the clinical trials for Erbitux, the drug she tried to obtain, involved a different type of cancer than the one she had. The complaint merely notes that she was not able to enroll in a clinical trial and thus could not obtain the drug. ${ }^{79}$ It does not say anything about her attempts to obtain the drug under a compassionate-use program. One article written about these events merely notes that "the drug company couldn't provide her with Erbitux for compassionate use." ${ }^{\text {"n }}$ Thus, nothing in the complaint, or in any other source, appears to indicate that the FDA rejected an attempt by the drug's manufacturer to supply her with the drug under some form of compassionate-use program.

David Baxter, a high school student who had colorectal cancer, is the second patient mentioned in the complaint. ${ }^{81}$ All the complaint says with regard to his circumstances is that, because he was not yet age eighteen, he was ineligible for enrollment in clinical trials. No mention is made of any efforts by his family to obtain access to unapproved drugs through compassionate-use programs.

The third patient mentioned in the complaint is Alita Randazzo, who also had colorectal cancer, but was age thirty-five. ${ }^{82}$ The complaint mentions that she "did not qualify for the clinical trial of Eloxatin in the U.S. and was not fortunate enough to get into the drug's limited compassionate use program." 83 No details are provided regarding why she was not able to enter that program. In particular, there is nothing suggesting that any specific FDA rules, as compared to decisions that the drug manufacturer made, prevented her from enrolling in that program.

Joel Oppenheim was the fourth and final patient whose case was discussed in the complaint. ${ }^{84} \mathrm{He}$ had multiple myeloma and attempted to enroll in clinical trials involving the drugs Revamid and Velcade, but initially did not meet the eligibility criteria because he had received prior treatments for his disease. There is no mention of his attempts, if any, to obtain these drugs under any compassionate-use programs.

\footnotetext{
78. Complaint, supra note 24 , at 6-9.

79. Id. at 7.

80. Kovach, supra note 24, at 26.

81. Complaint, supra note 24, at 7.

82. Id.

83. $I d$. at 8 .

84. Id. at $8-9$.
} 
Thus, looking at all of the four specific cases described in the complaint, there are relatively few, if any, facts indicating that FDA rules were the reason that these unfortunate patients were unable to get access to the drugs they sought. In only one of the four cases is there any mention of even an attempt to obtain the drug through a compassionateuse program. And even in that case, there are no facts suggesting that a particular FDA rule prevented the drug company from providing the drug.

The failure to provide these facts is not an accidental omission. For, even under the existing FDA regulations, the FDA is very likely to approve a request to provide a drug on a compassionate-use basis. In a recent conversation between Harvard professor Jerome Groopman and Richard Pazdur, the director of the FDA's Office of Oncology Drug Products, Pazdur noted that "the F.D.A. has rarely denied a patient's request to obtain an experimental drug under the compassionate-use provision." $85 \mathrm{He}$ was able to recall "only one instance in which the agency ha[d] done so: in the case of a boy with a brain tumor whose parents had refused to give him radiation therapy." ${ }^{\circ 6}$

Given that the FDA appears to almost uniformly approve requests for compassionate-use access to a drug, is it proper to conclude that the FDA rules are a barrier preventing terminally ill patients, such as Abigail Burroughs, from obtaining such drugs? The Alliance does in fact make such a claim, basing it not merely on the ability of drug manufacturers to get the approvals, but rather on what it views as an inappropriate condition that is imposed on drug companies if they wish to provide a drug for compassionate use. This condition is highlighted in the Alliance's complaint, where it challenges the "FDA's policy prohibiting the sale of investigational drugs" to patients. ${ }^{87}$ The complaint more specifically notes that the FDA should be required to allow drug companies "to charge for the drugs" they provide under a compassionateuse program, in contrast to the current rules, which permit "only cost recovery.", 88

The Abigail Alliance plaintiffs are correct in observing that drug manufacturers are subject to limitations on how much they can charge

85. Jerome Groopman, The Right to a Trial: Should Dying Patients Have Access to Experimental Drugs?, NEW YORKER, Dec. 18, 2006, at 45, 45-46.

86. Id. at 46 .

87. Complaint, supra note 24, at 10 (emphasis added).

88. Id. at 9-10. I am grateful to Peter Barton Hutt for highlighting during the symposium the importance to the plaintiffs of this aspect of the relief they sought. 
when they provide a drug on a compassionate-use basis. ${ }^{89}$ The plaintiffs thus raise a question that merits an answer: to what extent are these financial limitations a cause for drug manufacturers' refusal to provide drugs for compassionate-use purposes?

There is good reason to believe that the aspects of these rules relating to the amount that can be charged for the drugs are not playing the major role in the decisions by manufacturers about whether to provide compassionate-use access to their products. Drug companies have many more significant reasons that might lead them not to provide compassionate-use access. Former FDA official Richard Pazdur has

acknowledged that pharmaceutical companies currently have little motivation to comply with requests for experimental drugs. "There are some companies that flat out refuse to even get involved in expanded access .... We are told over and over by the industry that the F.D.A. will find some toxicity in the expanded-access program, and the evil Dr. Pazdur will take out his ruler and slap your hand, and the drug will be killed." 90

The strength of companies' reluctance to provide drugs on a compassionate-use basis is illustrated by a prominent story on the front page of the Wall Street Journal documenting one family's struggle. ${ }^{91}$ Four-year-old Penelope suffered from neuroblastoma, a somewhat rare type of cancer, and her parents believed that an experimental drug made by Neotropix Inc. might help her. The drug had heretofore been tested in only six human beings, and the company refused to provide the drug to Penelope. And, as the article pointed out, the "Food and Drug Administration isn't blocking the way." 92

In refusing to provide the drug, Neotropix indicated that

the drug may not be safe for a child and dispensing it would be bad business. "For us to provide the drug to this child would be to put at significant risk a small company with limited financial resources," [said

89. See 21 C.F.R. $\S 312.7$ (d) (2008). These rules are described in an FDA proposal to modify some of its rules, including providing greater specificity on what charges may be considered part of "cost recovery." Charging for Investigational Drugs, 71 Fed. Reg. 75,168, 75,170-71 (proposed Dec. 14, 2006) (to be codified at 21 C.F.R. pt. 312).

90. Groopman, supra note 85, at 46 (quoting Richard Pazdur).

91. Geeta Anand, Saying No to Penelope: Father Seeks Experimental Cancer Drug, but a Biotech Firm Says Risk Is Too High, WaLL St. J., May 1, 2007, at A1.

92. Id. 
a major investor]. "You could delay the opportunity for lots of patients to get this drug if you sidetrack it for one patient . . .."

The company CEO noted that "he wanted to help, but he thinks the drug is too early in testing to be used safely by a child." 94

Regarding the risks to the company from supplying the drug, there was concern that "the FDA [would] force Neotropix to put its trial on hold... if Penelope dies." 95 FDA officials had actually called the company and told them that would not happen, but the CEO remained concerned nonetheless. And, indeed, an FDA official who spoke to the reporter had commented that " "there aren't any absolutes.",96 Presumably, the FDA would not take action to put the trial on hold merely because Penelope died while she was taking the drug. But if there was clear evidence that the drug appeared to have harmed Penelope in some serious way, the FDA would certainly be required to look at that circumstance in deciding whether the drug was too risky to continue the study, at least without modification. There is no way that the FDA could ever make a promise to ignore what appeared to be valid evidence of a drug's risks.

If anything, the Wall Street Journal story underplays the true extent of the reluctance of many drug manufacturers to allow compassionateuse access to their unapproved drugs. While their concern about the liability issues, as expressed by Neotropix's CEO, is certainly a significant one, these companies often have even more significant worries. As Neotropix indicated, its fundamental concern is to make sure that the clinical trials take place in a prompt manner and that the needed information is collected to allow the FDA to make a decision about approving the drug. Such an outcome is not only beneficial to Neotropix and its bottom line, but to all of us as possible beneficiaries of the resulting medical advances.

And compassionate-use access, depending on the circumstances, poses a risk of delaying or perhaps even derailing those clinical trials. There are a variety of factors underlying this concern. A straightforward one is that there is often a very limited supply of a new drug. It might be very difficult and expensive to make. As a result, to the extent that some of that limited supply is used on patients who obtain it through

\footnotetext{
93. Id. (quoting managing partner of Quaker BioVentures).

94. Id.

95. Id.

96. Id. (quoting FDA cancer liaison program director).
} 
compassionate use, there may end up being less drug available for use in the clinical trials. ${ }^{97}$

But by far the most significant problem is that expanded compassionate-use access can threaten the ability of drug manufacturers to get patients to enroll in the clinical trials. There are a variety of reasons why, if a patient has a choice between getting an unapproved drug in a clinical trial and getting that drug directly from his or her doctor in a compassionate-use program, he or she would prefer the latter. $^{98}$ Perhaps most significantly, not all patients in clinical trials are actually treated with the experimental drug. Clinical trials often involve randomization, with some of the research subjects receiving the new drug while others being assigned to get the (usually not that effective) standard care. A patient with a terminal cancer who is contemplating enrolling in a clinical trial that offers only a 50\% shot at getting the new drug is likely to highly prefer a $100 \%$ chance of getting it through a compassionate-use program, if that option is available. ${ }^{99}$

There are other reasons for a patient to prefer a compassionate-use program to participation in a clinical trial. For instance, even if a trial does not involve randomization, its primary purpose is still not to treat the research subject, but rather to answer the research question. As a result, many aspects of the trial are designed in a way that the well-being of the research subject comes secondary to answering that question. ${ }^{100}$ While a doctor treating a patient as part of clinical care can-and indeed should, as a matter of law and ethics - tailor that care to meet the best interests of the patient, that is not true in a research study. The study's procedures are spelled out in a protocol, which will generally tie the researcher's hands in terms of what sorts of changes in treatment may be made to accommodate the needs of that patient. The goal of answering the research question is most commonly advanced by making sure that all of the subjects receive relatively similar treatment. That commonly means denying the subjects the right to the individualized care they

97. See, e.g., John A. Robertson, Controversial Medical Treatment and the Right to Health Care, HASTINGS CENTER ReP., Nov.-Dec. 2006, at 15, 17 ("Few companies conducting phase II studies are equipped on supply or logistical grounds to make [drugs] available to all who would want them ....").

98. The issue of the tension between allowing increased access to a drug outside of a clinical trial, yet still being able to get enough people to enroll in such trials, is explored in depth in JERRY Menikoff with Edward P. Richards, What the Doctor Didn't Say: The HidDEn TRUth ABOUT MEDICAL RESEARCH (2006).

99. See id. at 135-37 (discussing disclosure of availability of out-of-study treatment); Jerry Menikoff, The Hidden Alternative: Getting Investigational Treatments Off-Study, 361 LANCET 63, 63-66 (2003) (same).

100. MENIKOFF, supra note 98, at 15-19, 24-36. 
might otherwise receive from their doctors (including, for example, the important aspect of picking the dose of the drug that is most likely to treat the patient's cancer).

The tension between expanded-access programs and being able to recruit patients into clinical trials has long been recognized and has been a factor taken into account by the FDA in approving compassionate-use programs. As noted above, ${ }^{101}$ the proposed new compassionate-use rules are essentially a codification of what are already the FDA's practices. Those proposed rules are explicit in stating that compassionate use should not be permitted if it has the result of interfering in any way with clinical trials of the drug. ${ }^{102}$ Moreover, the congressional mandate for expanded access contained in the FDAMA itself contained exactly this limitation. ${ }^{103}$

Nor do these considerations come as news to the drug manufacturers. Their reluctance to provide experimental drugs through compassionateuse programs is not new, ${ }^{104}$ and though it might partly be related to some of the other issues discussed here (including liability and supply concerns), anxiety about cannibalizing the supply of likely research subjects no doubt remains a major factor.

Given these substantial reasons supporting the existing conduct of drug manufacturers in being less than eager to provide, let alone expand, compassionate-use programs, how much of a difference would be made by the one change that a new constitutional right might create: allowing the drug companies to get greater revenues from such programs by no longer being subject to the FDA's cost-recovery limitations? Not much of a difference, it would seem.

To override the existing drug company disincentives toward allowing substantial compassionate-use access, presumably the company would have to be looking at substantial new revenues from those

101. See supra note 75 .

102. The proposed new provision in the rules, 21 C.F.R. $\S 312.305(\mathrm{a})(3)$, states as a requirement for the approval of any expanded-access program that "[p]roviding the investigational drug for the requested use will not interfere with the initiation, conduct, or completion of clinical investigations that could support marketing approval of the expanded access use or otherwise compromise the potential development of the expanded access use." Expanded Access, supra note 68, at 75,151, 75,166 .

103. Id. at 75,149 .

104. See, e.g., MENIKOFF, supra note 98, at 6-8 (discussing historical methods of getting participants into studies); George J. Annas, Cancer and the Constitution-Choice at Life's End, 357 NEW ENG. J. MED. 408, 411 (2007) ("[T]he major bottleneck in the compassionate-use program has never been the FDA. The manufacturers have no incentives to make their investigational products available outside clinical trials. This is because direct access to investigational drugs by individuals may make it more difficult to recruit research subjects, and thus to conduct the clinical trials necessary for drug approval ....”); Robertson, supra note 97. 
programs. How might that occur? Two possibilities come to mind: the programs might be small, but there might be very high charges to patients; or, alternatively, the programs might be very large with more modest charges to patients. Both of these options seem of dubious viability.

Consider the small program with high charges. Since the drugs are experimental, it is likely that few, if any, insurance policies would cover these costs. Thus, patients who wanted to participate in these programs would have to pick up the costs out of their own pockets. The dilemma this presents for drug manufacturers is highlighted by some additional facts regarding Neotropix and the attempt by Penelope's parents to get her treated with the company's new drug. It so happens that her father, John London, was a "successful hedge-fund executive." $105 \mathrm{He}$ had worked for several years at one of the world's largest hedge funds, and had co-founded SuttonBrook Capital, which had turned into a fund with two billion dollars in assets. ${ }^{106}$ Given that hedge fund managers commonly take home extraordinary amounts of money, even by Wall Street standards, it seems possible that London could himself have provided funding to Neotropix that exceeded the twenty million dollars that it was then trying to raise.

But is this an arrangement with which a company like Neotropix would be comfortable? Should the newest drugs go to those families with the deepest pockets? In many ways, the facts relating to experimental drugs are similar to those regarding transplantable organs. There is often a limited supply, and thus issues of fairness regarding who lives and dies are highlighted, even more so than already exists in a health care system that fails to provide universal access. It is highly unlikely that drug companies testing life-and-death treatments are going to feel comfortable with presenting themselves as catering to the ultrarich while those less well-off are unable to get access to the most promising, cutting-edge products.

On the other hand, consider the option of a large compassionate-use program with more modest charges to each patient. The very size of such a program likely increases the risk that its existence would have an influence on the ability of the drug company to recruit patients for its clinical trials. Only if the disease being treated were extremely common would there be enough patients to supply both the clinical trials and the compassionate-use program. And even in that circumstance, it might be

105. Anand, supra note 91 .

106. Id. 
nearly impossible to structure the two programs so that patients had sufficient incentives to enter the clinical trials as opposed to getting the drug through expanded access. Given that we are dealing with terminal diseases such as cancer, some or even many patients would likely lie or manipulate their circumstances so as to make themselves ineligible for the clinical trials, if that was a requirement for participating in the expanded-access program. Thus, such large programs would likely be workable in only extremely limited circumstances, such as when enrollment in the clinical trials had already been largely completed, and the company was merely waiting for the results of the trial.

The bottom line, then, is that the much sought-after new constitutional right would have little impact. Yes, such a right might have the result of altering FDA limitations on the ability of drug manufacturers to provide experimental drugs on a compassionate-use basis. But to a large extent, the companies already have strong incentives not to want to do that, incentives that have little to do with the FDA's rules. The only FDA rule whose elimination might create new incentives would be the agency's barrier to a company's earning substantial profits from a compassionate-use program. However, as I have attempted to demonstrate, there are few circumstances in which such profits are likely to be substantial enough to override the existing disincentives.

\section{WHERE THE REAL DILEMMA OVER ACCESS TO UNPROVEN TREATMENTS LIES}

Although a new constitutional right to experimental drugs would be unlikely to bring much change to our existing health care system, some of the issues raised by the Abigail Alliance litigation have continuing relevance. As the preceding Part has shown, the attempt by the plaintiffs to get early access to such drugs poses a very real conflict between the interests of dying patients desperate to get a chance at any possible treatment, even those that are largely a shot in the dark, and society as a whole, which will benefit from the knowledge learned in clinical trials. The existing laws, combined with the reality of how drugs are marketed, have resolved that dilemma by giving the drug manufacturers the authority to strike the balance between expanded access and maintaining conditions that allow sufficient enrollment of subjects into research studies. While those companies are thus required to make very difficult decisions as they determine when to grant compassionate-use access to one or another dying patient who sees a particular drug as a last chance at 
treatment, that role for them is one that is endorsed by the current regulatory scheme.

But those very issues raised in the Abigail Alliance litigation-in particular, the tension between access to unproven drugs and the ability to perform medical research-also exists in another scenario, one that may in the end prove far more consequential than the realm of non-FDAapproved drugs. And in this other scenario, the resolution of the tension between helping current patients versus future patients is far less certain, and the legal issues are in many ways more troubling.

This scenario is the use of prescription-only drugs, drugs that already have FDA approval for at least one use, for a purpose that is different from that approved use. This is a well-recognized phenomenon and is perfectly legal. Once the FDA has approved a drug for treating one disease, that drug is on the market, and doctors can prescribe it for treating other diseases. ${ }^{107}$ This use of a drug is commonly referred to as off-label use, since doctors prescribe the drug in a manner that differs from the labeling that the FDA approves when it allows marketing of the drug.

From a purely logical viewpoint, there are good arguments for concluding that this arrangement does not make much sense. If a drug cannot be marketed until the drug is proven both safe and effective for a given purpose - exactly the issue that the plaintiffs ran up against in urging the Supreme Court in Rutherford to grant them access to Laetrile - why should a patient be able to get access to a drug for some different medical problem? ${ }^{108}$ It might well be the case that the drug would be unsafe if used to treat patients with that problem, or it might be ineffective, or it might be both unsafe and ineffective. Any of those three circumstances would appear to raise issues very similar to those that exist for a drug that is not on the market. Nonetheless, it is recognized that the applicable laws give the FDA relatively little authority over the actions of a doctor in prescribing a marketed drug for a use that is different from the approved use. ${ }^{109}$ The doctor's actions constitute the practice of medicine, and the FDA does not directly regulate the practice of medicine.

The off-label prescribing of medications is not only a wellrecognized practice; it constitutes a huge part of modern-day medicine. It is hard to get very accurate numbers, but estimates suggest that up to

107. See, e.g., Steven R. Salbu, Off-Label Use, Prescription, and Marketing of FDA-Approved Drugs: An Assessment of Legislative and Regulatory Policy, 51 FLA. L. REV. 181, 189-90 (1999).

108. See supra notes 18-22 and accompanying text.

109. See Salbu, supra note 107, at 190. 
sixty percent of the prescriptions written in the United States involve offlabel prescribing. ${ }^{110}$ Without a doubt, many hundreds of millions of such prescriptions are written each year.

It is important to recognize that just because a prescription involves an off-label use, it does not necessarily follow that the patient is receiving an experimental or highly risky treatment. Many of those offlabel prescriptions represent treatment choices that are well-recognized by doctors and that can even constitute the standard-care treatment for a particular medical problem. It takes a great deal of time and effort-and often millions of dollars - to do the testing and generate the proof that will convince the FDA to change the labeling for a drug and recognize that it can be labeled as safe and effective for a new use. Given those barriers, many treatments become well-accepted by doctors in spite of never ending up as part of the official labeling information for the drug. ${ }^{111}$

But it is the opposite end of the world of off-label use that I want to turn to now. While many off-label uses are essentially standard care, other off-label uses are the source of a large portion of the clinical trials taking place. Indeed, while the Abigail Alliance litigation might suggest to the public that most of the new treatments being tested are brand-new, not-yet-approved drugs, that suggestion is far from the truth. It is getting harder and harder for drug companies to find brand-new drugs. The category of "new molecular entity" - a new drug that is a brand-new chemical, and not merely a tweaking of some already-approved drug-is actually becoming a shrinking segment of the drugs that drug manufacturers are testing. ${ }^{12}$ In contrast, the growth area is in "me-too" drugs. ${ }^{113}$ One company merely makes a slight change in a chemical compound that is already approved and marketed by a competitor, thus enabling it to take a share of the market for that existing drug, though contributing little to the development of genuine breakthroughs in medical treatment.

110. See, e.g., Michael I. Krauss, Loosening the FDA's Drug Certification Monopoly: Implications for Tort Law and Consumer Welfare, 4 GEO. MASON L. REV. 457, 472 (1996).

111. See Salbu, supra note 107, at 188 .

112. See, e.g., James M. Hoffman et al., Projecting Future Drug Expenditures-2004, 61 AM. J. HEALTH-SYS. PHARMACY 145, 150 (2004) ("A trend of fewer new drug approvals and a shrinking drug pipeline has emerged and will continue for the next few years.... The number of [new molecular entities] approved peaked in $1996 \ldots$. . but since then there has been a steady decrease in approvals ...." (citation omitted)).

113. See, e.g., Marcia Angell, The Truth About the Drug Companies: How They DeCEIVE Us AND WhAT to Do ABOUt IT 16-17 (2004) ("The stream of new drugs has slowed to a trickle, and few of them are innovative in any sense of that word. Instead, the great majority are variations of oldies but goodies-'me-too' drugs.”). 
While brand-new drugs represent a shrinking segment of the treatments undergoing clinical trials, off-label uses of existing drugs present a very different image. Largely unknown to much of the public, they constitute the growth industry segment in clinical research. Merely take a look at any of the major listings of clinical trials. ${ }^{114}$ A recent examination of cancer clinical trials, for example, demonstrated that over forty percent of the trials involved not the testing of a new drug, but rather off-label uses of existing drugs. ${ }^{115}$

This state of affairs should not be all that surprising. Many of the greatest breakthroughs in medicine are the result of discovering some new use of an old drug. Consider how many millions of people are taking aspirin these days, not for aches and pains, but for the far more important purpose of preventing heart attacks and strokes. And in the cancer field, a very substantial portion of the progress in treating or curing many cancers has come from new permutations, doses, and schedules of old stalwarts from the chemotherapy arsenal.

Thus, for patients such as the plaintiffs in the Abigail Alliance litigation-people who are suffering from an incurable terminal disease - the last-chance therapy they are seeking might best be found not in a clinical trial testing some brand-new drug, but rather from a trial testing off-label uses of approved drugs. Suppose that they find out about such a study, either on their own or because their doctors tell them about it and ask them to enroll in it. An important question immediately arises: Should they enroll in that study?

Given their interest in being treated with the new treatment, namely the off-label use, such patients should presumably compare what would happen to them in the clinical trial with the options they would have outside the trial. As noted above, clinical trials often involve the randomization of subjects to two or more arms, and only in some of those arms will a subject receive the new treatment. Thus, participation in the trial does not guarantee receiving that new treatment.

Those considerations are identical to what takes place in trials involving non-FDA-approved drugs. But the analysis changes dramatically as the focus shifts to the alternatives to participating in the trial. As the previous Parts of this Article explained, for a non-FDAapproved drug, it will usually be difficult for the patient to receive the drug outside of the clinical trial. The very fact that a patient is eligible

114. E.g., ClinicalTrials.gov, http://www.clinicaltrials.gov (last visited March 12, 2008) (registry maintained by the U.S. National Institutes of Health).

115. David B. Resnik et al., The Failure to Disclose Off-Study Treatment: An Analysis of Oncology Consent Forms (2008) (unpublished manuscript, on file with author). 
for the trial means that a drug manufacturer, even if it occasionally is willing to create compassionate-use programs for some of its products, is highly unlikely to make such a person eligible for the compassionate-use program. And there is nothing legally wrong with the company doing that. Nor does it appear unethical for it do so. It is perfectly appropriate for the drug company to worry about making sure that the clinical trial enrolls enough subjects. While of course it has its own profit motive at stake, achievement of that goal also is likely of benefit to society. Moreover, the company owes no particular duty to a person who could enroll in the clinical trial but would prefer to receive the drug outside of the trial.

Now let us examine the situation where the trial involves an off-label use of an FDA-approved drug or combination of drugs. In this circumstance, it is far more likely that the patient contemplating enrollment in the trial could obtain the new treatment outside of the study. As noted above, since the drug is already on the market, there is no legal barrier to any physician's prescribing that drug for that new purpose. ${ }^{116}$

In asking the patient to enroll in the study, what should the researcher disclose about the possible option of getting the new treatment outside of the study? That question does not arise in a vacuum. There are a set of federal regulations that govern the conduct of most clinical trials, and they provide various protections to potential research subjects. They create specific duties that researchers owe to research subjects. ${ }^{117}$ In particular, the researchers must obtain the informed consent of the subjects before the subjects can be enrolled in a study. ${ }^{118}$ And in getting informed consent, researchers need to inform the potential subjects about the alternatives to participating in the study. ${ }^{119}$

116. The physician might of course be concerned with whether she might be committing malpractice in using the drug in this off-label manner. Assuming, however, that there are no good alternative treatments for the patient's condition, and that the possible benefits from use of the drug are reasonable in relationship to the risks it poses, it will often be reasonable to treat the patient with the drug. Under those circumstances, it is highly unlikely that treating the patient with the drug will constitute malpractice. See MENIKOFF, supra note 98, at 37-50 (discussing legal protection of patients receiving nonstandard care).

117. See Jerry Menikoff, Could Tuskegee Happen Today?, 1 St. LouIS U. J. Health L. \& POL'Y (forthcoming 2008) (discussing claims that such duties are relatively weak in certain types of studies).

118. See Carl H. Coleman et al., The Ethics and Regulation of Research with Human SUBJECTS 297-369 (2005) (discussing informed consent generally and the role of informed consent in the research setting).

119. 45 C.F.R. $\S 46.116(a)(4)(2008)$. 
The informed consent obligations imposed on researchers by the federal regulations are not especially burdensome, and in many ways they represent the minimal duties that a society might think appropriate for asking people to participate in research studies where participation might not be in their best interests. The duties find their roots in the Nuremberg Code, the document that came out of the inquiry into what the Nazis did to many people in prisoner-of-war camps. ${ }^{120}$ That Code included the requirement of obtaining informed consent as the first and most substantial point in its list of ten requirements.

Surely, if it were known that there was an alternative to participating in a clinical trial that many subjects would prefer, and these subjects were not being informed about that option, then the ethics of that clinical trial would be highly questionable. Researchers would effectively be using a type of fraud to get people into the study. Yet, quite surprisingly, that is what appears to be happening in a large percentage of clinical trials. Where the clinical trial involves the off-label use of marketed drugs, and thus it would be perfectly legal for a doctor to prescribe them to patients outside of the study, it remains that people being asked to enroll in the study are often not told about the out-of-study option. ${ }^{121}$ Even though the opportunity to be sure of getting the new treatment, instead of the fifty percent chance of that happening in a randomized clinical trial, would be greatly preferred by many patients, they are frequently not given that information.

A recent examination of this phenomenon, as it applies to cancer studies listed on the federal government's clinictrials.gov Web site, revealed that in more than eighty percent of the consent forms for studies involving off-label uses, the subjects were not told about their option of getting the treatments outside of the study. ${ }^{122}$ And there was no statistical difference between those studies that were conducted by private companies (such as pharmaceutical manufacturers), and those that were funded by public entities (such as the federal government).

Why is there an unwillingness to reveal crucial information to patients being asked to participate in clinical trials? While there is no proof, an obvious conclusion is that there is concern that if this information were given to the patients, fewer of them would enroll in the

120. See 2 Trials of War Criminals before the Nuernberg Military Tribunals under CONTROL COUNCIL LAW No. 10, at 181-82 (1949), available at http://www.hhs.gov/ohrp/ references/nurcode.htm.

121. See, e.g., MeniKoff, supra note 98, at 124-41 (discussing the legality and ethics of the practice of not disclosing a research subject's options); Menikoff, supra note 99.

122. See Resnik et al., supra note 115. 
studies. The entity conducting the study would of course be less successful in its goals, and, depending on the type of study, society at large would suffer as a result of the delays in generating new medical knowledge.

And this concern is far from hypothetical. There is excellent evidence, for example, that when patients have a terminal disease, and are contemplating which treatment to get, they will opt for obtaining the promising-but-unproven treatment directly from a doctor instead of enrolling in a clinical trial where they will have a substantially smaller (usually fifty percent) chance of being randomized to that treatment. Perhaps the best example of this phenomenon is the story of high-dose chemotherapy followed by autologous bone-marrow transplantation (often called HDC-ABMT) as a treatment for metastatic breast cancer. ${ }^{123}$

During the early 1990s, a few doctors tried using this treatment on their patients and seemed to be getting much better results than with the standard lower-dose chemotherapy. ${ }^{124}$ Clinical trials were begun to randomize women with breast cancer between standard care and this new treatment to see if the high-dose treatment really was as good as it seemed. But since the new treatment involved the off-label use of FDAapproved drugs, nothing prevented doctors from offering the treatment directly to patients. And that is exactly what many doctors were doing. The new treatment received wide publicity, and as a result of that publicity, it became extremely difficult to get women to enroll in the randomized trials. Most women wanted the new treatment, not the fifty percent chance of being assigned to it in a randomized trial. Eventually, the researchers were able to enroll enough women to complete the trials, and the results demonstrated that the high-dose chemotherapy was no better than the standard lower-dose chemotherapy, which produced far less pain and suffering for the patients. ${ }^{125}$

That series of events is certainly far from ideal. On the other hand, the solution that seems to be followed in all too many clinical trialsassuring that there is adequate enrollment in clinical trials by denying prospective research subjects information about their option of getting the experimental treatment directly from a doctor-is both illegal and unethical. Thus, this state of affairs is far more troubling than what happens in clinical trails involving non-FDA-approved drugs where the tension between the interests of current and future patients has at least been resolved, if not perfectly, by a set of accepted rules. The proper

123. See MENIKOFF, supra note 98, at 124-29.

124. Id. at $125-26$.

125. See id. at $125,128$. 
solution to the dilemma of research involving off-label uses still remains to be worked out. Certainly, any such solution must require that deception no longer be a key element in getting people to enroll in clinical trials. There are other legally acceptable ways to encourage enrollment, and an exploration of those methods deserves greater public attention. ${ }^{126}$

\section{CONCLUSION}

Determining the extent to which people dying from untreatable diseases should have access to experimental drugs is a task with no easy solution. Purely from the viewpoint of the best interests of such patients, there are compelling reasons for and against such access. But even beyond the interests of the patients themselves, there is the important additional factor of determining how increased access might diminish researchers' ability to conduct clinical trials and determine the safety and efficacy of such drugs.

With regard to drugs that are not yet FDA-approved for any use, the legal regime currently in place resolves those tensions in a particular manner. Even if there were found to be a constitutional right on the part of such patients to receive unproven drugs, it would do little to actually alter their access to the drugs. Such a right would merely prevent the government from interfering with their attempts to obtain the drugs, and it is the drug manufacturers, not the government, that are currently the biggest roadblock preventing such access. The existing resolution may or may not be ideal, but nonetheless it at least appears to be one that is endorsed by the law and where most of the parties involved are conforming to the law.

In contrast, with regard to the situation of testing FDA-approved drugs for new uses, the situation appears quite different. There, the tension between the interests of current and future patients appears to all too commonly work itself out by a practice that denies participants in clinical trials the information they might have wanted most in making the decision to enroll in those trials. Such a practice is neither ethical nor

126. See id. at 239-51. One of the more interesting approaches is that which appears to be used in the world of pediatric oncology. Given that it is such a small community, those doctors have informally agreed to try to restrict the use of experimental treatments outside of clinical trials. In essence, this creates an arrangement similar to what exists for non-FDA-approved drugs. Id. The legality of the actions of these doctors remains open to question, but the agreement nonetheless suggests the possibility of changing the laws so as to restrict patient access to off-label treatments in certain circumstances. Nonetheless, that would clearly be a difficult change to implement and successfully police. 
legal. It is time that efforts were made to end this practice, and to come up with a regime that, as with the testing of non-FDA-approved drugs, produces a result that is reasonable from a policy perspective and involves neither illegal nor immoral conduct. 